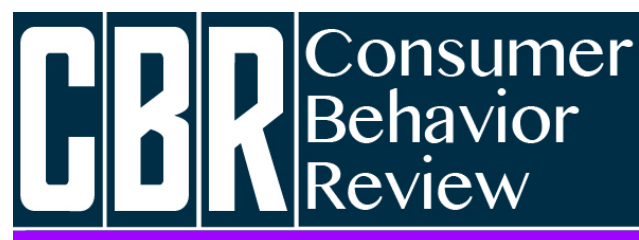

Revista Comportamento do Consumidor
Aguiar, E. C. \& Policarpo, M. C. (2018). Fenomenologia da Percepção: Uma abordagem para a investigação de experiência de consumo. Consumer Behavior Review, 2(2), 7283.
ISSN: 2526-7884

Editor: Prof. Dr. Marconi Freitas da Costa

Email da revista: cbr@ufpe.br
Avaliação: Double blind review

Recebido: 30 de junho de 2018

Aceito: 19 de outubro de 2018

\title{
FENOMENOLOGIA DA PERCEPÇÃO: UMA ABORDAGEM PARA A INVESTIGAÇÃO DE EXPERIÊNCIAS DE CONSUMO
}

\author{
Edvan Cruz Aguiar \\ Manoela Costa Policarpo
}

Edvan Cruz Aguiar é Professor do Programa de Pós-Graduação em Administração da Universidade Federal de Campinha Grande - UFCG. E-mail: edvan.ed@gmail.com.

Manoela Costa Policarpo é Mestranda do Programa de Pós-Graduação em

Administração da Universidade Federal de Campinha Grande - UFCG. E-mail: manoelacpolicarpo@gmail.com. Os autores agradecem aos avaliadores pelos comentários para melhoria do artigo.

\begin{abstract}
Resumo
No campo de estudos do comportamento do consumidor, o fenômeno experiência de consumo tem despertado o interesse de pesquisadores e praticantes, especialmente nas últimas três décadas. A perspectiva do consumo experiencial surge para auxiliar na compreensão do comportamento de consumo voltado para a busca de fantasias, sentimentos e diversão, que se refere a um estado de consciência essencialmente subjetivo e com uma variedade de significados. No intuito de auxiliar pesquisadores do comportamento de consumidor, este ensaio objetiva propor uma abordagem metodológica para investigar o fenômeno experiência de consumo à luz da fenomenologia da percepção, do filósofo francês Merleau-Ponty (1908-1961). Apreende-se a experiência de consumo enquanto ocorrência particular do indivíduo, em que há relevância de cunho emocional e afetivo, fundamentada na interação entre os estímulos presentes nos produtos e serviços consumidos. 0 modelo proposto sistematiza o processo de apreensão da experiência de consumo por meio da identificação dos significados inerentes às atividades associadas ao comportamento do consumidor.

Palavras-chave: Experiência de consumo, Inspiração fenomenológica, Percepção, Método de pesquisa.
\end{abstract}

Esta obra está licenciada com uma Licença Creative Commons Atribuição 4.0 Internacional.

\section{INTRODUÇÃO}

Desde o início dos anos 80, pesquisadores do comportamento do consumidor vêm buscando ampliar a abordagem de investigação desta área. Até então, os consumidores eram vistos exclusivamente como tomadores de decisão 
racional. Atualmente, consideram-se também aspectos subjetivos como o hedonismo, a estética, o prazer e as fantasias no ato de consumir, em especial devido à contribuição de autores como Holbrook e Hirschman (1982).

Nos últimos anos as experiências de consumo têm se tornado uma prioridade ainda maior nos estudos sobre o comportamento do consumidor (Solomon, 2016). Nessa perspectiva, a abordagem do marketing experiencial surge para auxiliar na compreensão da experiência de consumo, voltada para a busca de fantasias, sentimentos e diversão, que se refere a um estado de consciência essencialmente subjetivo e com uma variedade de significados simbólicos, hedônicos e estéticos (Holbrook \& Hirschman, 1982; Schmitt, 1999).

Considerando as interações do cliente como os elementos que compõem a sua experiência de consumo, quanto maior a importância de respostas subjetivas, maior será o destaque atribuído aos aspectos hedônicos de consumo (Addis \& Holbrook, 2001), posto que os sentimentos e as emoções surgem das interações que o cliente vivencia na interação com produtos, serviços, pessoas e ambiente. Neste sentido, entende-se que a experiência está intrinsecamente relacionada ao fenômeno do consumo, devendo ser tratada como importante elemento da vida do consumidor. Pois, segundo Cerqueira (2008), as experiências têm o poder de modificar a maneira como um indivíduo age em determinadas situações e ao mesmo tempo proporcionar novas experiências.

$\mathrm{Na}$ contemporaneidade, $\mathrm{o}$ papel das experiências tem assumido cada vez mais relevância na compreensão das relações entre mercado e consumo, bem como na formação da identidade do consumidor, tendo em vista que o entendimento desse fenômeno se debruça sobre aspectos subjetivos e multifacetados que envolvem o comportamento humano e social (Carù \& Cova, 2003). Para Aguiar (2011), a experiência apresenta um papel fundamental na compreensão dos aspectos associados ao consumo, porém, no que se refere à pesquisa do comportamento do consumidor, existe uma necessidade por investigações que apontem abordagens alternativas.

A fenomenologia existencial corresponde a uma possibilidade quanto ao estudo da experiência de consumo, o qual combina a filosofia do existencialismo com o método da fenomenologia (Thompson, Locander, \& Pollio, 1989). A experiência é definida como um episódio subjetivo na transformação (ou construção) do sujeito, que leva a minimizar a dimensão cognitiva (Barbosa, 2006). Por sua vez, o consumo pode ser entendido como um estado íntimo e intrínseco em que o indivíduo vivencia em algum modo de aquisição (Correa, Pinto, \& Batinga, 2016). Deste modo, é coerente afirmar que há um alinhamento entre a visão subjetiva do fenômeno experiência de consumo e o pensamento de que esta corresponde à ocorrência(s) que pode(m) levar a transformação do indivíduo.

Diante do exposto, este ensaio teórico objetiva propor uma abordagem metodológica para investigar o fenômeno experiência de consumo, à luz da fenomenologia da percepção, do filósofo francês Merleau-Ponty (1908-1961). Sua escolha justifica-se por apreender os fenômenos por meio da percepção do sujeito (relação de reciprocidade e interatividade) a partir de uma perspectiva de experiência. Em outras palavras, na experiência vivida pelo sujeito, ele descobre a presença de outros aspectos que correspondem tanto a pessoas como os demais elementos passíveis de serem percebidos. Logo, considerando a experiência de consumo em seus mais variados contextos enquanto objetivo de investigação, entende-se que a abordagem de Merleau-Ponty seja a mais adequada.

Esta abordagem faz contraponto ao modelo positivista de pesquisa, o qual reduz o homem a uma explicação de causalidade. Ela reconhece o indivíduo enquanto sujeito percebedor que se constitui ao passo em que se relaciona com o mundo (objeto da percepção), por meio das experiências vivenciadas e atribuição de significados a estas. No que diz respeito a presente proposta, a ênfase encontra-se nas experiências de consumo, isto é, um sujeito das próprias experiências. É a partir dessa abordagem fenomenológica que se fundamenta este trabalho.

Assim, além desta parte introdutória, o presente trabalho tem sua estrutura distribuída da seguinte forma: inicialmente é discutida experiência de consumo e seu significado para o consumidor; em seguida é apresentada a fenomenologia da percepção, sob a perspectiva do pensamento de Merleau-Ponty e a definição 
de alguns termos fenomenológicos para fins de esclarecimento da abordagem; por conseguinte expõe-se o método proposto para investigação da experiência de consumo; e por fim as considerações finais concernentes.

\section{EXPERIÊNCIA E SIGNIFICADO DE CONSUMO}

A experiência de consumo é aqui visualizada a partir da perspectiva das ciências sociais, compreendida como uma ocorrência particular do indivíduo, em que há relevância de cunho emocional e afetivo, fundamentada na interação entre os estímulos presentes nos produtos e serviços consumidos (Holbrook \& Hirschman, 1982).

0 entendimento sobre as experiências de consumo envolve a tentativa dos clientes em alcançar algum propósito na compra, isto é, aspectos relativos à satisfação que, são balizados diferentes níveis de reação: racional, emocional, sensorial, físico ou espiritual (Damian \& Merlo, 2014). Portanto, há a experiência quando o indivíduo tem alguma sensação ou adquire algum conhecimento a partir do contato estabelecido entre os elementos criados pelo provedor de uma oferta (Pullman \& Gross, 2003). Atualmente, a experiência tem sido considerada um fator chave para o sucesso das organizações, assumindo cada vez mais um importante papel nas relações entre os consumidores e o mercado. Tal fenômeno constitui base importante para o estudo do marketing, pois se volta cada vez mais para aspectos subjetivos e multifacetados (Carù \& Cova, 2003).

As experiências sensoriais têm se tornado uma prioridade ainda maior quando há escolhas entre opções concorrentes. Argumenta-se que a experiência de consumo corresponde a um meio relevante para compreender as sociedades pósindustriais (Antéblian, Filser, \& Roeder, 2014; Lanier \& Rader, 2015) Aspectos subjetivos como o hedonismo, o prazer e as fantasias no ato de consumir tornam-se relevantes. Apreende-se a experiência como um episódio subjetivo, ao passo que enfatiza as emoções e os sentidos vividos no ato de consumir, o que leva a minimizar a dimensão cognitiva. Holbrook e Hirschman (1982) afirmam que corresponde a um estado de consciência essencialmente subjetivo e com uma variedade de significados simbólicos, hedônicos e estéticos.

Em termos de significado do consumo, Mowen e Minor (2003) afirmam que os consumidores constroem culturalmente, dentro de um contexto social, os significados atribuídos a objetos e sensações que o circundam. Isto é, o homem tende a adotar uma postura mental balizada por pressupostos adquiridos no contexto em que está imerso (Macedo, Boava, \& Antonialli, 2012). Sendo assim, esta significação advém por meio de um processo de construção social, no qual os consumidores adquirem produtos e serviços não apenas para satisfazer suas necessidades materiais, mas também atender demandas hedônicas e sociais.

Para McCracken (2003), o consumo possui significados que ultrapassam os aspectos utilitários, quando enfatiza a transferência de significados por meio dos bens de consumo, instituições e o próprio indivíduo quando do ato de consumir. Entende-se que a construção do significado se configura por meio de relações recíprocas entre três elementos, a saber: texto (conteúdo dos anúncios de produtos e serviços), prática (hábitos e costumes presentes no diadia do indivíduo) e história (contexto anterior do meio social) (Berger \& Luckmann, 2009; Hirschman, Scott, \& Wells, 1998).

A utilidade dos produtos não é o único fator determinante nas decisões de compra, já que os significados simbólicos envolvidos no ato de consumir também exercem papel fundamental nesse processo (Firat \& Venkatesh, 1995), de modo que estes significados podem ser tanto idiossincráticos, quanto comumente partilhados com outros consumidores. Além disso, podem ser utilizados pelos indivíduos para sustentar a sua imagem ou criar uma nova representação de si mesmos.

0 estudo do consumo relaciona-se diretamente à vida humana e os seus significados. Portanto, o seu significado é o resultado de uma construção social, intermediada pelos produtos, serviços e o contexto envolvido na sua oferta. Todo indivíduo nasceu em uma estrutura social objetiva, dentro da qual encontra os outros significativos que se encarregam de sua socialização (Berger \& Luckmann, 2009). Nesse sentido, pode-se ainda afirmar que o consumo corresponde a uma experiência social. 
A fenomenologia existencial corresponde a uma possibilidade quanto ao estudo da experiência de consumo, o qual combina a filosofia do existencialismo com o método da fenomenologia (Thompson et al., 1989). Deste modo, é coerente afirmar que há um alinhamento entre a visão subjetiva do fenômeno experiência de consumo e o pensamento de que esta corresponde à ocorrência(s) que pode(m) levar a transformação do indivíduo.

Schmitt (1999), considerado o precursor do marketing experiencial - abordagem que tem por objetivo compreender aspectos que proporcionem a criação de experiências ao consumidor, sendo estas assumindo um caráter holístico - acredita que as experiências ocorrem como resultado do encontro de uma experiência vivenciada ou por meio de objetos. A experiência fornece sentimentos, emoção, cognição, comportamento e valores relacionais que substituem valores funcionais (Schmitt, 1999; 2010).

A experiência de consumo envolve todos os aspectos de oferta de uma empresa: a qualidade do atendimento, os recursos de publicidade, embalagens, produtos, serviços e a facilidade de uso (Meyer \& Schwager, 2007, p. 117). Tal abordagem assume uma visão mais abrangente para a compreensão dos elementos que compõem o fenômeno experiência no que diz respeito aos estudos contemporâneos envolvendo o consumo.

Schmitt (1999; 2010) define cinco diferentes tipos de experiências ou módulos estratégicos experienciais (SEMs), a saber: experiências sensoriais (SENSE); experiências afetivas (FEEL); criação de experiências cognitivas (THINK); experiências físicas, comportamentais e estilo de vida (ACT) e experiências de identidades sociais que resultam da relação a grupos de referência e cultura (RELATE). Esse mesmo autor reforça a diferença entre o marketing tradicional, pautado exclusivamente nos aspectos racionais dos consumidores, como os recursos e os benefícios dos produtos e serviços, e o marketing experiencial, que ressalta a perspectiva emocional do consumo.

Em contraste com o estreito foco nos recursos funcionais e benefícios, o marketing experiencial foca a experiência do consumidor. Experiências ocorrem como resultado do encontro de uma experiência vivenciada ou por meio de objetos. "A experiência fornece sentimentos, emoção, cognição, comportamento e valores relacionais que substituem valores funcionais" (Schmitt, 1999, p. 57).

Um aspecto considerado importante quando se trata de consumo experiencial diz respeito às emoções, posto que a experiência de consumo pode estabelecer estados afetivos e desencadear reações internas no indivíduo, contribuindo positivamente as atitudes e os comportamentos dos consumidores (Groeppel-Klein, 2005; Havlena \& Holbrook, 1986).

Entende-se que, quanto maior importância for dada às respostas subjetivas dos clientes, maior destaque será atribuído aos aspectos hedônicos de consumo, uma vez que os sentimentos e as emoções surgem das interações que o cliente vivencia, podendo ocorrer com funcionários, outros clientes e o ambiente como um todo. No entanto, é importante refletir também sobre até que ponto os clientes estariam dispostos "a pagar" pelo envolvimento em uma experiência mais enriquecida (Damian \& Merlo, 2014).

Diante do exposto, se faz pertinente destacar que a pesquisa do consumidor precisa incorporar em suas análises elementos de noção experiencial de consumo (Pinto \& Lara, 2011). Segundo estes mesmos autores, ainda que a área, sobretudo no Brasil, tenha se desenvolvido nos últimos anos, na perspectiva da noção experiencial do consumo, permanecem alguns desafios no tocante à compreensão do fenômeno.

A despeito de uma consolidada literatura na área concernente à experiência de consumo, entende-se que para investigar este fenômeno existe uma lacuna concernente à existência de um modelo que sistematize o processo de apreensão da experiência de consumo por meio da identificação dos significados inerentes às atividades associadas ao comportamento do consumidor. $\mathrm{Na}$ próxima seção são apresentados e discutidos alguns conceitos sobre a fenomenologia existencial de MerleauPonty.

\section{A FENOMENOLOGIA EXISTENCIAL DE MERLEAU-PONTY}

Conforme mencionado anteriormente, o estudo proposto parte de uma perspectiva fenomenológica para compreender o fenômeno 
experiência de consumo, a partir das vivências dos sujeitos, e suas implicações quanto ao consumo experiencial. Para tal, tem-se como aporte teórico a fenomenologia existencial de Merleau-Ponty. Nesse sentido, algumas considerações iniciais precisam ser feitas no sentido de circunscrever tal perspectiva.

Ressalta-se que Edmund Husserl (19591938) é considerado o fundador da fenomenologia e um dos grandes pensadores clássicos do ocidente, tendo sua obra influenciado diversos filósofos, dentre eles Merleau-Ponty. A fenomenologia é interpretada como uma postura que objetiva descrever as essências como aparecem na consciência, em que o esforço centra-se nos conteúdos da consciência e na sua característica essencial, ou seja, a intencionalidade.

Para Merleau-Ponty (2006), corresponde ao estudo das essências, essência da percepção, essência da consciência, por exemplo. Portanto, trata-se de captar os fenômenos vividos e vivenciados numa tentativa de fazer uma descrição direta das experiências, sem nenhuma consideração concernente à sua gênese psicológica ou de explicações causais. Logo, se refere a uma aproximação, por meio do método fenomenológico, à essência do fenômeno.

\section{Definição de termos fenomenológicos}

Para uma melhor compreensão da discussão teórica concernente à fenomenologia da percepção e sua relação com o contexto da proposta de pesquisa aqui apresentada, faz-se relevante recuperar a definição de alguns termos. Os termos apresentados seguem a orientação de Matthews (2010).

Alteridade: processo pelo qual há a percepção da existência do outro além do sujeito. Ou seja, o homem não existe como consciência fechada em si mesmo, pois corresponde à ideia de ser no mundo, mundo das relações. Este conceito está atrelado ao entendimento de intersubjetividade.

Comportamento: corresponde às reações que as pessoas têm como respostas às experiências vivenciadas por estes, a partir de determinados estímulos. Entende-se como uma maneira de lidar com o mundo, que é internamente dirigido e não causado externamente.
Experiência: contato com o mundo, na perspectiva do sujeito, em que a sua constituição parte do vivenciar, sendo relevante quando refletida e conscientemente apreendida. Ao longo de sua trajetória o indivíduo acumula experiências e, por conseguinte, apreende contextos, estabelece relações e se define.

Fenomenologia: estudo das essências, essência da percepção, essência da consciência, na tentativa de realizar uma descrição direta das experiências vivenciadas pelas pessoas em um mundo já dado.

Intencionalidade: refere-se à consciência da existência de algo. Ou seja, o conhecimento e a consciência são sempre o conhecimento e a consciência de algo, de modo que o subjetivo não é um mundo a interior a parte, mas necessariamente relacionado ao mundo de que se tem consciência.

Intersubjetividade: constituição do mundo de relações pessoais, que resulta da percepção do sujeito em relação ao mundo e ao outro. Parte-se da ideia de que a existência humana não é inteiramente solitária e puramente mental.

Percepção: diz respeito ao envolvimento prático com as coisas. Em outras palavras, não é apenas ter uma ideia a respeito, mas lidar com isso de alguma forma. Entende-se que as relações cognitivas com os objetos são elas mesmas dependentes de um tipo de envolvimento mais primitivo com eles, que deve ser descrito antes mesmo de ser possível de entender $o$ significado de conceitos mais específicos. Viver no mundo vem primeiro, saber sobre ele vem depois.

Redução fenomenológica: postura de suspender os julgamentos prévios, de colocar de lado todas as noções preconcebidas a fim de observar os fenômenos com neutralidade.

A definição e entendimento de alguns termos fenomenológicos são necessários para a compreensão da discussão teórica sobre a fenomenologia e a sua aplicabilidade nas pesquisas relacionadas ao comportamento do consumido, sobretudo no que concerne às suas experiências de consumo. A seguir é discutido a fenomenologia da percepção.

\section{A fenomenologia da percepção}

Este tópico discute o núcleo central do pensamento de Merleau-Ponty, de modo que 
não trabalhará as suas últimas produções, que só foram publicadas após a sua morte, isso porque corresponde ao que se conhece como seu projeto inacabado. Portanto, o recorte interpretativo situa-se em seu projeto inicial, com ênfase em sua obra clássica, A fenomenologia da percepção.

Nesse sentido, a fenomenologia é considerada, antes de qualquer coisa, mais uma forma de pensar do que um sistema filosófico (Pinto \& Santos, 2008). A fenomenologia corresponde ao estudo das essências, mas não de forma abstrata. Ou seja, visa compreender os conceitos que são usados a partir da apreensão do seu papel na vida humana. Portanto, captar fenomenologicamente a essência da percepção é compreender como a percepção efetivamente funciona nas relações dos indivíduos com o mundo circundante e com outros indivíduos (Matthews, 2010).

Compreender os fenômenos vivenciados é tarefa da fenomenologia, que visa descrever as experiências como são, sem nenhuma consideração de sua origem na psicologia ou de explicações causais. Todavia, é importante considerar o papel da redução fenomenológica no entendimento de Merleau-Ponty. Ao contrário do que pensa Husserl entende-se que não é possível retirar-se completamente da subjetividade que lhe é inerente para apreender os fenômenos, considera a redução fenomenológica como a busca por uma neutralidade axiológica que permitirá ao pesquisador aproximar-se ao máximo das essências.

Diante do exposto, a perspectiva fenomenológica aqui apresentada é uma filosofia que se propõe a descrever as experiências vivenciadas pelas pessoas com ênfase no contexto de consumo, se atém aos contextos experienciais de consumo, numa tentativa de esclarecer o significado dos conceitos utilizados pelos indivíduos. Para Andriolo (2016), a orientação fenomenológica tem o intuito de descrever as vivências e a percepção dos indivíduos, contemplando dimensões a partir de narrativas e estímulos advindos do espaço social.

Assim, a percepção, enquanto envolvimento prático corresponde a um elemento fundamental no estudo das essências das experiências (Merleau-Ponty, 2006). Além disso, a experiência não corresponde a uma mera coleção de objetos separados, e sim coisas e situações como um todo contextualizado (Aguiar, Farias, \& Melo, 2013). Perceber significa entender de alguma perspectiva, não é captar passivamente os estímulos que veem de fora e interpretá-los, e sim um contato direto com tais elementos, que toma forma de envolvimento ativo com as coisas que cercam o indivíduo. Tal envolvimento não naturalmente apenas cognitivo, já que parte desse envolvimento também é emocional, prático, estético e imaginativo (Holbrook \& Hirschman, 1982; Matthews, 2010).

Entende-se que cada organismo é um conjunto significativo para uma consciência que o conhece, não uma coisa que repousa em si (Ferraz, 2009). A abordagem fenomenológica merleau-pontyana não objetiva descrever condições formais da experiência, mas debruçar-se a explorar as vivências particulares em que os parâmetros perceptivos de organização dos dados são exercidos por um sujeito engajado nas situações do cotidiano. É importante dizer que descrever a percepção não é coletar dados psicológicos, e sim explicitar um modo originário de manifestação e constituição do ser, do que é percebido pelo indivíduo, na condição de objeto intencional e seu significado.

Nas palavras de Jean Paul Sartre (2012), contemporâneo de Merleau-Ponty, para compreender-se enquanto ser no mundo, faz-se necessário passar pela existência do outro, a intersubjetividade. Em outras palavras, o outro é indispensável à existência do eu. Por analogia, e em consequência disto, pode-se afirmar que os significados às experiências de consumo são condicionados à interação do consumidor com o meio, e assim sendo, as suas interpretações são estabelecidas e (re)configuradas a partir das escolhas feitas de engajamento com suas práticas de consumo.

Portanto, as experiências assumem papel importante tanto na constituição da ideia que o sujeito tem de si como nas escolhas que ele faz, e no caso deste trabalho, são inerentes ao consumo de experiências e os significados atribuídos a estas. Os indivíduos se situam no mundo a partir da intencionalidade desse mundo, ao passo em que reflete sobre o que percebe, em uma dialética interativa, vai se constituindo e dando sentido ao mundo que o circunda Sartre (2012, p. 58) se alinha a essa ideia quando afirma: 
Dizer que nós determinamos os valores não significa outra coisa senão que a vida não tem sentido em si, a priori. Antes de começarmos a viver, a vida, em si, não é nada, mas nos cabe dar-lhe sentido, e o valor da vida não é outra coisa senão este sentido que escolhermos [...] 0 existencialismo nuca tomará o homem como fim, pois ele sempre está por fazerse.

Considerando que o homem corresponde ao conjunto de suas experiências e das suas relações, os significados que ele atribui às experiências de consumo são estabelecidos em função destas vivências prévias. Da mesma maneira que ele define sua identidade a partir da relação intersubjetiva com o mundo, os significados que são atribuídos a eventos posteriores igualmente exercem influência dos acontecimentos vividos a priori, mesmo entendendo que o sujeito é um vir a ser, em constante processo de construção.

Uma questão importante presente na 'fenomenologia da percepção' que reforça o caráter subjetivo inerente ao comportamento humano e os significados que são atribuídos às experiências refere-se ao papel do corpo enquanto a condição de vivenciar o mundo. A apreensão do sentido ou dos sentidos se faz pelo corpo, tratando-se de uma expressão criadora, a partir dos diferentes olhares sobre o mundo (Nóbrega, 2008).

Nessa mesma perspectiva, a experiência do corpo corresponde ao lócus originário de sentidos, posto que a noção de percepção aqui discutida relaciona-se com a representação mental, mas um evento de corporeidade. A compreensão fenomenológica da percepção é construída com base no diálogo com a psicologia, entendida como uma interpretação sempre provisória e incompleta, isto porque a realidade é tida como infinita e o conhecimento finito.

Logo, a ênfase na investigação fenomenológica está em compreender os objetos (o mundo) ao redor com um significado para quem o percebe. 0 exemplo de Matthews (2010, p. 74) ajuda no entendimento: "A maçã é, para mim, não meramente um objeto com certa forma e tamanho a um metro de distância de meus olhos, mas algo para comer e desfrutar". Assim, falar de intencionalidade e subjetividade é falar sobre uma maneira de compreender comportamentos segundo características internar do sujeito investigado, que se direcionam para certos objetos e pelas quais estes possuem certo significado para ele (Merleau-Ponty, 2006).

Portanto, afirmar que as pessoas executam determinadas atividades significa dizer que elas possuem algum propósito em fazê-las. Logo, o comportamento é internamente direcionado e não algo que vem, como uma lógica reducionista de causalidade, externamente. Merleau-Ponty defende essa ideia quando diz que o comportamento vem de dentro e é dirigido por e dotado de intenção e significado. Ele reconhece que os processos cognitivos/neurais de fato existem em função de situações do cotidiano, mas não terão nenhum significado até que o indivíduo cujo o cérebro ocorre esses processos encare o evento como expressivo.

0 posicionamento já mencionado em seções anteriores, dessa proposta de pesquisa, com relação ao estudo do comportamento humano, não pode ser analisada sob uma perspectiva de causalidade que negligencia a subjetividade inerente ao homem. Trata-se de recusar a interpretação causal sobre mecanismos psicológicos de que fala a psicanálise, por exemplo (Furlan, 2000).

A compreensão de significados pressupõe investigar a experiência vivida, considerando o todo e as partes (Faria, 2012). Desse modo, o intuito é desvelar as estruturas essenciais e relacionamentos do fenômeno, que incluem os atos da consciência nos quais os fenômenos aparecem. Outro aspecto importante é que também requer, por parte do pesquisador, ser capaz de partilhar algo com a pessoa cujo comportamento se pretende apreender, ou seja, ser capaz de ver o mundo no ponto de vista do sujeito investigado.

Ressalta-se também que nessa abordagem fenomenológica há um afastamento do pensamento metafísico. Nesse aspecto MerleauPonty recebeu influência do filósofo alemão, Martin Heidegger, ao afirmar que as coisas que cercam os indivíduos adquirem significado pelo papel que desempenham em suas vidas, e não por uma classificação puramente intelectual. Esse entendimento se alinha com a ideia de ser no mundo, cunhada por Heidegger, que enfatiza o concreto sobre o abstrato.

0 entendimento do eu como substrato do habitus, apresentada por Pelizzoli (2002) em 
seu livro intitulado ' $\mathrm{O}$ eu e a diferença: Husserl e Heidegger', também consubstancia a ideia central dessa proposta de abordagem de pesquisa:

O eu puro é, por conseguinte, substrato do habitus; eu que se descobre como origem e constituinte do mundo, como um eu que existe, ou que é nas suas experiências atuais e potenciais. Ele aparelha e coordena as formas, as maneiras próprias de ser, veem de suas próprias condições e possibilidades [...] Por conseguinte, o homem-pensador já não vive de modo ingênuo, mas com a possibilidade de retomar - reduzir constantemente o domínio que verdadeiramente dá sentido e orienta a existência (Pelizzoli, 2002, p. 53).

Esta relação de ser no mundo é bastante presente em Merleau-Ponty, pois considera como um diálogo interativo entre ambos, de modo que a existência de um precede e depende do outro, e vice-versa. Argumenta-se que ao viver nossas vidas, necessariamente envolvemo-nos com o mundo de várias maneiras (práticas, emocionais e teóricas). Logo, só podemos fazer isso porque o mundo já está aí para que nos envolvamos com ele, da mesma maneira que só podemos ter um diálogo se há outra pessoa com a qual conversar (Matthews, 2010).

0 essencial para a fenomenologia e captar a percepção viva, em via de realização, e nesse sentido pressupõe-se deixar de lado os preconceitos (Merleau-Ponty, 2006), mesmo entendendo que não pode livrar-se completamente, já que há subjetividade tanto do investigado como do investigador. Assim, trata-se mais de uma postura axiológica assumida pelo pesquisador no intuito de se chegar às essências.

Tal aspecto não invalida a presente proposta de investigação ou perde seu caráter de cientificidade. Isto porque corresponde a uma perspectiva epistemológica, que como tal possui seus próprios critérios, sem falar que se trata de uma abordagem alternativa, fora do mainstream, para compreender o fenômeno experiência de consumo e os significados a ele atribuídos.

\section{ABORDAGEM METODOLÓGICA SOB INSPIRAÇÃO FENOMENOLÓGICA}

0 objetivo do método fenomenológico é descrever a estrutura total da experiência vivida, os significados que a experiência tem para os sujeitos que a vivenciam, por meio de observações e entrevistas objetivando descrever os dados como eles se apresentam. A fenomenologia preocupa-se com a compreensão do fenômeno, não com a sua explicação (Martins, 1993).

Para Gill (2002), uma boa descrição deve ser um registro tão detalhado, quanto possível, do discurso a ser analisado. Este mesmo autor ainda recomenda registrar as falas sobrepostas, entonações, respirações, dentre outros elementos que ajudem a enriquecer a análise. Seguindo esta orientação, o pesquisador fará uso de equipamento que grave imagem e som dos entrevistados e dos contextos de serviços (Flick, 2004).

Correspondendo a uma abordagem qualitativa de pesquisa, o método fenomenológico não visa generalizações. Contudo, procura manter o rigor, não segundos os critérios de validade e confiabilidade quantitativos, por apresentarem dimensões pessoais, sendo mais apropriadamente pesquisados mediante a abordagem qualitativa (Martins \& Bicudo, 1989; Merriam, 2001).

A fenomenologia existencial utiliza a comunicação interpessoal para chegar à compreensão dos significados da experiência vivida pelo indivíduo, enfatizando a experiência consciente deste sujeito (intenção), permitindo assim chegar-se ao nível de descrição. A partir do uso de ilações lógicas, a redução da experiência consciente permite ao pesquisador localizar aqueles elementos de significado que estão empiricamente presentes na situação, sendo percebidos e expressos por meio do discurso do sujeito de pesquisa (Martins, 1993).

A análise da estrutura do fenômeno situado é uma das possibilidades da pesquisa fenomenológica. Na Figura 1, segue a esquematização da proposta de abordagem metodológica para investigação do fenômeno experiência de consumo aqui discutida, à luz da fenomenologia da percepção (Merleau-Ponty, 2006), inspirada em Martins (1993) e Bicudo (2011). 
Figura 1- Abordagem fenomenológica para investigar experiência de consumo

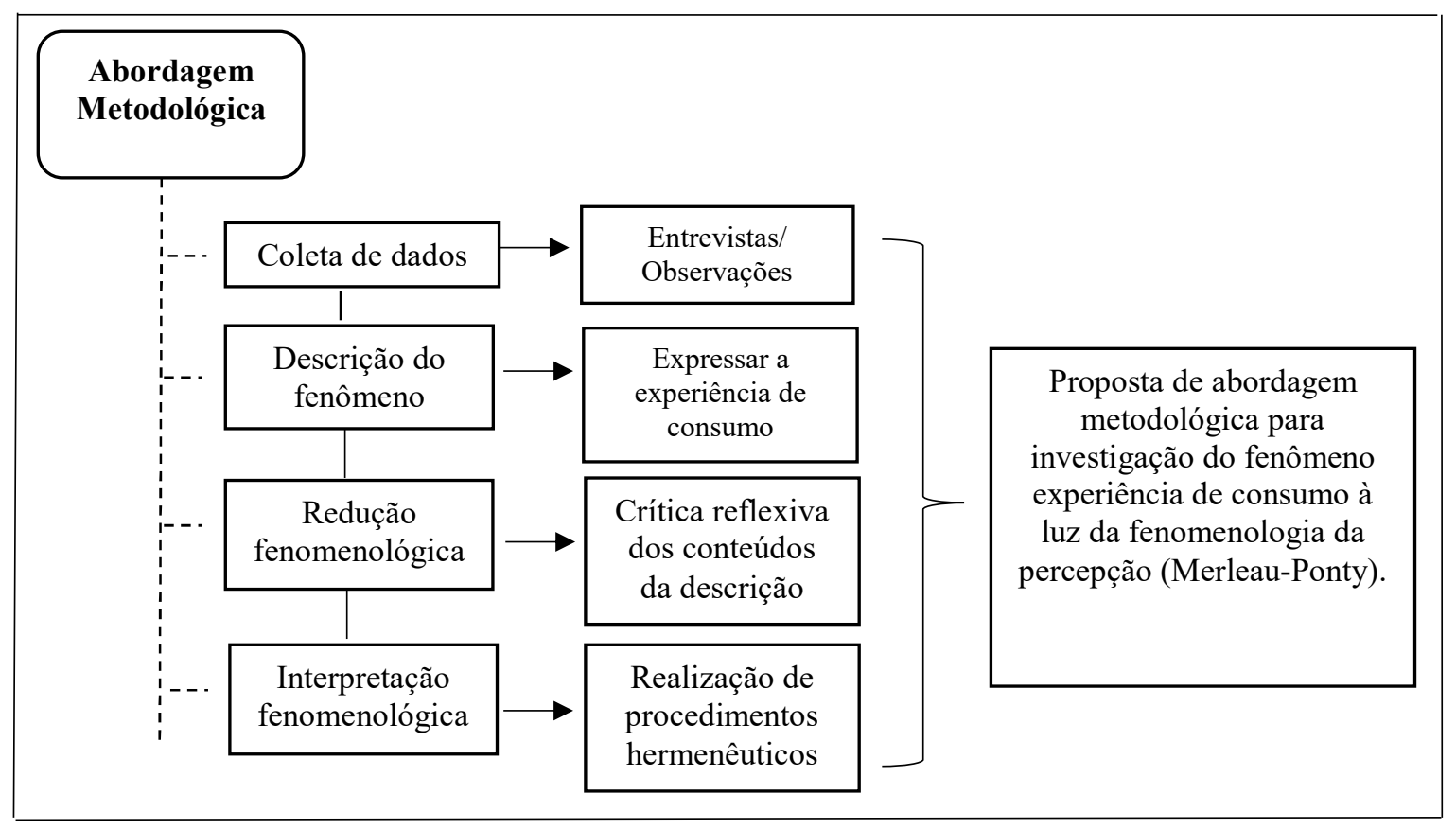

Fonte: Desenvolvido pelos pesquisadores (2018).

A abordagem fenomenológica para investigar experiência de consumo apresentada na Figura 1 possui quatro etapas. Inicialmente faz-se a coleta de dados por meio de entrevistas (preferencialmente não estruturadas para melhor alinhamento à pesquisa qualitativa) e observações, podendo ser participante ou não participante. Posteriormente, de posse dos dados, há a descrição do fenômeno. Nesta etapa o pesquisador retrata e expressa textualmente a experiência consciente do sujeito quanto à situação de consumo vivenciada.

A etapa seguinte corresponde à redução fenomenológica, na qual é feita uma crítica reflexiva dos conteúdos da descrição. Esta etapa compreende a manutenção da descrição na sua forma original, procurando analisar a experiência vivenciada sem a interferência de conceitos pessoais e/ou teóricos, além da criação de uma perspectiva gestalt, em que observador centra-se na tematização dos dados da descrição. Ou seja, identificação, no discurso do sujeito de pesquisa, dos pontos relevantes, também denominado de unidades de significados.

Por fim, há a interpretação fenomenológica, etapa em que o pesquisador realiza a verificação do significado do fenômeno investigado pela ótica dos sujeitos de pesquisa, por meio da análise ideográfica, na qual o pesquisador analisa e interpreta cada um dos discursos separadamente, resultando na formulação de sua própria compreensão concernente ao fenômeno, assim como realiza uma análise nomotética, buscando por convergências entre as perspectivas de todos os sujeitos de pesquisa objetivando ampliar a apreensão dos significados atribuídos.

Ressalta-se que, na abordagem fenomenológica enquanto método, o pesquisador assume o papel de coparticipante do processo na apreensão dos fenômenos e significados. Para tanto, requer uma postura reflexiva, sobretudo do ponto de vista axiológico em termos de validade e confiabilidade da pesquisa realizada (Merriam, 2001).

A fenomenologia existencial utiliza a comunicação interpessoal para chegar à compreensão dos significados da experiência vivida pela pessoa. Focaliza a experiência consciente deste sujeito (intenção) que permite limites epistemológicos a serem definidos em nível de descrição. Mediante o uso de inferências lógicas, a redução da experiência consciente permite ao pesquisador localizar aqueles elementos de significado que estão empiricamente presentes na situação, sendo 
percebidos e expressos mediante o discurso do sujeito.

Apreender os fenômenos vivenciados é tarefa da fenomenologia, uma vez que descreve as experiências como estas realmente são, sem nenhuma consideração quanto à origem psicológica ou às explicações causais. A perspectiva fenomenológica aqui apresentada é uma filosofia antifilosófica em termos platônicos (metafísicos), pois descreve as experiências vividas pelas pessoas que se atém aos contextos experienciais de consumo. Portanto, trata-se de uma tentativa para esclarecer o significado dos conceitos utilizados pelos indivíduos.

O consumo possui sentidos que ultrapassam os aspectos utilitários, sobretudo quando ressalta a transferência de significados através dos bens, das instituições e do próprio indivíduo (Berger \& Luckmann, 2009; Hirschman et al., 1998; Mccracken, 2003). Entende-se que a construção dos significados se dá por meio da relação recíproca entre três elementos, a saber: texto (conteúdo dos anúncios de produtos e serviços), prática (hábitos e costumes presentes no dia a dia do indivíduo) e história (contexto anterior do meio social).

0 modelo proposto sistematiza o processo de apreensão da experiência de consumo por meio da identificação dos significados inerentes às atividades associadas ao comportamento do consumidor. É importante ressaltar que, muito embora sua elaboração se constituiu à luz da fenomenologia da percepção, esta proposta não se configura enquanto teoria. Ou seja, trata-se de um modelo teórico que delineia objetivamente as etapas envolvidas no estudo da experiência de consumo, o que constitui contribuição e originalidade da proposta.

\section{CONSIDERAÇÕES FINAIS}

0 presente ensaio, aqui apresentado e discutido, pretende contribuir com os estudiosos do consumo ao propor uma abordagem, sob inspiração fenomenológica, enquanto método para apreender o fenômeno experiência de consumo. A fenomenologia da percepção correspondeu à perspectiva adotada por entender que perceber significa enxergar de alguma perspectiva, não captar passivamente os estímulos que veem de fora e interpretá-los, mas sim estabelecer contato direto com tais elementos, de tal sorte que haja o envolvimento ativo com as coisas que cercam $o$ indivíduo/consumidor.

Tal envolvimento não é, naturalmente, apenas cognitivo, já que parte dele também é emocional, prático, estético e imaginativo (Holbrook \& Hirschman, 1982; Matthews, 2010). Além disso, a experiência não corresponde apenas a uma coleção de objetos separados, mas sim a situações como um todo. Entende-se que cada organismo é um conjunto significativo para uma consciência que o conhece, não algo que repousa em si (Ferraz, 2009).

Ressalta-se que a abordagem proposta não tem como finalidade descrever condições formais da experiência; na realidade, deseja explorar as vivências particulares em que os parâmetros perceptivos de organização dos dados são exercidos por um consumidor engajado nas situações de consumo. Portanto, descrever a percepção não é coletar dados psicológicos, e sim explicitar um modo originário de manifestação e constituição do ser, a partir do que é percebido por este consumidor, na condição de objeto intencional e os seus significados (Nóbrega, 2008).

A compreensão dos significados pressupõe investigar a experiência vivida, considerando o todo e as partes (Faria, 2012). Deste modo, o intuito é desvelar as estruturas essenciais e os relacionamentos do fenômeno, que incluem os atos da consciência nos quais os fenômenos aparecem. Vale ressaltar que o pesquisador deverá ser capaz de partilhar algo com o indivíduo cujo comportamento se pretende apreender, ou seja, deverá ver o mundo do ponto de vista do sujeito investigado.

Espera-se que o trabalho possa auxiliar pesquisadores do comportamento de consumidor, especialmente no que range a apreensão do fenômeno experiência de consumo em seus mais diversos cenários, da descrição e da construção de conhecimento nesta área, ampliando assim seu corpo teórico. Cabe mencionar ainda que a fenomenologia mostra-se particularmente interessante na pesquisa em administração, especialmente quando voltada ao contexto do consumo e nas interações de serviços (Carvalho \& Vergara, 2002; Moreira, 2002). 
Neste sentido, algumas sugestões de aplicação desta abordagem são indicadas: (1) identificação dos significados atribuídos pelos consumidores aos ambientes de consumo e a relação com suas experiências passadas e correntes; (2) compreensão da maneira como a presença dos outros clientes e os provedores de serviços são percebidos pelo consumidor e como isso afeta sua experiência de consumo; (3) investigar quais as sensações e as associações do consumidor frente aos elementos estéticos, físicos e sociais presentes nos mais diversos ambientes de consumo; (4) descrever experiências de consumidores compulsivos a fim de compreender seu significado.

É importante dizer que as recomendações aqui apresentadas não possuem a pretensão de esgotarem todas as possibilidades, tendo mais um caráter provocativo aos acadêmicos da área a se sentirem estimulados a adotarem esta abordagem metodológica (sob inspiração fenomenológica), e assim expandir as possibilidades de apreensão do fenômeno experiência de consumo o conhecimento construído na área.

\section{REFERÊNCIAS}

Addis, M., \& Holbrook, M. B. (2001). On the conceptual link between mass customisation and experiential consumption: an explosion of subjectivity. Journal of consumer behaviour, 1(1), 50-66.

Aguiar, E. C. (2011). Elementos sensoriais da atmosfera de serviços gastronômicos centrados na experiência e seus significados para o consumidor. Dissertação de Mestrado em Administração, Universidade Federal de Pernambuco, Recife, PE, Brasil.

Aguiar, E. C., Farias, S. A., \& Melo, F. V. S. (2013). 0 significado de cores e iluminação em uma atmosfera de serviços gastronômicos. Revista Brasileira de Administração Estratégica, 6(3), 291-303.

Andriolo, A. A. (2016). Paisagem da Cidade Histórica e Turística: Fenomenologia da Experiência Estética. Caderno Virtual de Turismo, 16(3), 91-105.

Antéblian, B., Filser, M., \& Roederer, C. (2014). Consumption experience in retail environments: a literature review. Recherche et Applications en Marketing, 28(3), 82-109.

Barbosa, M. L. A. (2006). O significado do consumo de serviços de restaurante a partir da experiência de compra. Tese de Doutorado em
Administração, Universidade Federal de Pernambuco, Recife, PE, Brasil.

Berger, P. L., \& Luckmann, T. (2009). A construção social da realidade (30a ed.). Petrópolis: Vozes.

Bicudo, M. A. V. (2011). Pesquisa qualitativa segundo a visão fenomenológica. São Paulo: Cortez.

Carù, A., \& Cova, B. (2003). Revisiting consumption experience: a more humble but complete view of the concept. Marketing Theory, 3(2), 267286.

Carvalho, J. L. F. S., \& Vergara, S. C. (2002). A fenomenologia e a pesquisa dos espaços de serviços. Revista de Administração de Empresas, 42(3), p. 78-91.

Cerqueira, T. Estilos de aprendizagem de Kolb e sua importância na educação. Revista Estilos de Aprendizagem, 1(1), 109-123.

Correa, R. S., Pinto, M. R., \& Batinga, G. L. (2016). A Beleza na escuridão: um "olhar" sobre a experiência de consumo por mulheres deficientes visuais em serviços de beleza e estética. Revista Ciências Administrativas, 22(2), 371-395.

Damian, I. P. M., \& Merlo, E. M. (2014). Experiência de Consumo e o Papel da Qualidade do Serviço em Concessionárias de Veículos. CONTEXTUS - Revista Contemporânea de Economia e Gestão, 12(1), 07-28.

Faria, J. H. (2012, setembro). Dimensões da matriz epistemológica em estudos em administração: uma proposição. Anais do Encontro Nacional de Pós-Graduação e Pesquisa em Administração, Rio de Janeiro, RJ, Brasil, 36.

Ferraz, M. S. A. (2009). Fenomenologia e ontologia em Merleau-Ponty. Campinas: Papirus.

Firat, A. F., \& Venkatesh, A. (1995). Liberatory Postmodernism and the Reenchantment of Consumption. The Journal of Consumer Research, 22(3), 239-267.

Flick, U. (2004). Uma introdução à pesquisa qualitativa (2a ed.) Porto Alegre: Bookman.

Furlan, R. (2000). A noção de "comportamento" na filosofia de Merleau-Ponty. Estudos de Psicologia, 5(2), 383-400.

Gill, R. (2002). Análise de discurso. In M. W. Bauer \& G. Gaskell (Eds.). Pesquisa qualitativa com texto, imagem e som. Petrópolis: Vozes.

Groeppel-Klein, A. (2005). Arousal and consumer instore behavior. Brain Research Bulletin, 67(1), 428-437.

Havlena, W. J., \& Holbrook, M. B. (1986). The varieties of consumption experience: comparing two typologies of emotion in consumer behavior. Journal of Consumer Research, 13(1), 394-404.

Hirschman, E. C., Scott, L., \& Wells, W. B. (1998). A model of product discourse: linking consumer 
practice to cultural texts. Journal of Advertising, 1(27), 33-50.

Holbrook, M. B., \& Hirschman, E. C. (1982). The experiential aspects of consumption: consumer fantasies, feelings and fun. Journal of Consumer Research, 9(2), 132-140.

Lanier, C. D., \& Rader, C. S. (2015). Consumption experience: an expanded view. Marketing Theory, 15(4), 487-508.

Macedo, F. M. F., Boava, D. L. T., \& Antonialli, L. M. (2012). A fenomenologia social na pesquisa em estratégia. RAM, Rev. Adm. Mackenzie. 13(5), 171-203.

Martins, J. (1993). Um enfoque fenomenológico do currículo: educação como poíesis. São Paulo: Cortez.

Martins, J., \& Bicudo M. A. (1989). A pesquisa qualitativa em psicologia: fundamentos $e$ recursos básicos. São Paulo: Moraes.

Matthews, E. (2010). Compreender Merleau-Ponty. Petrópolis: Vozes.

McCracken, G. (2003). Cultura \& consumo. Rio de Janeiro: Mauad.

Merleau-Ponty, M. (2006). Fenomenologia da percepção. São Paulo: Martins Fontes.

Merriam, S. B. (2001). Qualitative research in practice: examples for discussion and analysis. The Jossey-Bass higher and adult education series.

Meyer, C., \& Schwager, A. (2007). Understanding customer experience. Harvard Business Review, 85(2), 117-126.

Moreira, D. A. (2002). O método fenomenológico na pesquisa. São Paulo: Pioneira.

Mowen, J. C., \& Minor, M. S. (2003). Comportamento do consumidor. São Paulo: Prentice Hall.
Nóbrega, T. P. (2008). Corpo, percepção e conhecimento em Merleau-Ponty. Estudos de Psicologia, 13(2), 141-148.

Pelizzoli, M. (2002). O eu e a diferença: Husserl e Heidegger. Porto Alegre: EDIPCRS.

Pinto, M, R., \& Santos, L. L. S. (2008). Em busca de uma trilha interpretativista para a pesquisa do consumidor: uma proposta baseada na fenomenologia, na etnografia e na grounded theory. Revista de Administração de Empresas - Eletrônica, 7(2), 25.

Pinto, M. R., \& Lara, J. E. (2011). As experiências de consumo na perspectiva da teoria da cultura de consumo: identificando possíveis interlocutores e propondo uma agenda de pesquisa. Cadernos EBAPE.BR. 9(1), 37-56.

Pullman, M. E., \& Gross, M. A. (2003). Ability of experience design elements to elicit emotions and loyalty behaviors. Decision Sciences, 35(3), 551-578.

Sartre, J. P. (2012). O existencialismo é um humanismo (2a ed.). Petrópolis: Vozes.

Schmitt, B. (1999). Experiential Marketing. Journal of Marketing Management, 15(1), 53-67.

Schmitt, B. (2010). Experience Marketing: concepts, frameworks, and consumer insights. Foundations and Trends in Marketing, 5(2), 55112.

Solomon, M. R. (2016). O comportamento do consumidor: comprando, possuindo e sendo. (11a ed.). Porto Alegre: Bookman.

Thompson, C. J., Locander, W. B., \& Pollio, H. R. (1989). Putting consumer experience back into consumer research: The philosophy and method of existential-phenomenology. Journal of consumer research, 16(2), 133-146.

\title{
Phenomenology Perception: An approach to the investigation of consumer experiences
}

\begin{abstract}
On consumer behavior field, the experiential consumption phenomena has aroused the interest of researchers and practitioners, especially in the last years. The experiential consumption perspective arises to support the understanding of consumption behaviors towards seeking of fantasies, feelings $e$ entertainment, which refer to consciousness state essentially subjective, and with a variety of meanings. In order to help researchers on consumer behavior area, this essay aims to propose a methodological approach to investigate the consumption experience phenomenon based on the phenomenology of perception, from french philosopher Merleau-Ponty (1908-1961). Consumer experience is assumed as a particular instance of the individual, where there is relevance of emotional and affective nature, based on the interaction between the stimuli present in the products and services consumed. The proposed model systematizes the process of apprehending consumer experience by identifying meanings inherent in activities associated with consumer behavior.
\end{abstract}

Keywords: consumer experience; phenomenological inspiration; insight; research method. 